\title{
Law, Ethics and Tech Aspects for an Irrevocable BlockChain Based Curriculum Vitae Created by Big Data Analytics Fed by Internet of Things, Sensors and Approved Data Sources
}

\author{
Vasilios Kanavas \\ Department of Business Administration \\ West Macedonia Univ of Applied Sciences, 50100 Kozani, Greece
}

Athanasios Zisopoulos (Corresponding author)

Faculty of Mathematics and Informatics, University of Sofia Saint Clement Ochridsky

Blvd "James Bourchier" 5, 1164 g.k. Lozenets, Sofia, Bulgaria

E-mail: zisopoulos.athanasios.dim@gmail.com

Konstantinos Spinthiropoulos

Department of Business Administration

West Macedonia Univ of Applied Sciences, 50100 Kozani, Greece

Received: October 14, 2018 Accepted: November 8, 2018 Published: November 10, 2018

doi:10.5296/ijmis.v3i1.13774 URL: https://doi.org/10.5296/ijmis.v3i1.13774

\begin{abstract}
Our general idea is to adopt Blockchain Ledger Technology for volunteered recording of business skills to formulate an irrevocable irresistible Curriculum Vitae to be processed by Recruiting agencies. The desperate well-educated jobless people of our times rely on recruiting agencies to analyze their qualification and find them a descent work. The general process starts with personal data feed automatically from sensors to an irrevocable BlockChain. At the final stage recruiting companies read these data, they process and offer a better job. A modified Time-Series is used to store work history and skills as the most important part of a Curriculum-Vitae. Every moment of our work life is recorded accordingly.
\end{abstract}




\section{Macrothink}

International Journal of Management Innovation Systems

ISSN 1943-1384

These data are collected from various IoT sources like; Internet of things, Word, Excel computer file headers, URL fingerprints, Data Centers \& Banks Big Data. It looks like self-slavery although according to GDPR the necessary consent must be freely given, specific, informed and unambiguous. In order to obtain freely given consent, it must be given on a voluntary basis. We attempted a primitive social research. In our University young people, they prefer to follow the blockchain recruiting route at a rate of $96 \%$ while in a local prefecture only $1 \%$ endorses the technology for unemployment.

Keywords: Curriculum Vitae, Recruiting, GDPR, Regtech, Lawtech, smart contracts, Blockchain, IoT 


\section{Mll Macrothink}

\section{Introduction}

Our general idea is to adopt Blockchain Ledger Technology for volunteered recording of business skills to formulate an irrevocable irresistible Curriculum Vitae to be processed by Recruiting agencies.

The hard-working people of our times cannot find a respectable job due to incapability of society to adopt technologies. Machines caused these problems; this same machinery could help fight unemployment altogether. Tax evasion increases every day. Public awareness for alternative tax options is increasing. People suffer from limited health insurance and pension funds. New tax objects could be selected from: robots, productivity tools, invention patents, software applications, auto bots, crawler internet robots, bitcoin protocol bits and hundreds of others. As a result of all these people cannot find an appropriate job. The life circle of job finding is Education at the eight EU levels: training and skill acquirement; preliminary student placement; and actually, paid work. This life circle could start all over and recursive. The passport to enter the next high salary work is the curriculum vitae. Initially was a structured text fully compatible with Chicago Manual of Style (Manus, 2009; Dellavalle, 2003). This approach is adopted by CEDEFOP and the European key players in recruitment. In our times the hypertext approach of LinkedIn is gaining attention (Skule, 2004; Miles, 2011). In the LinkedIn CV job skills are intermixed with degree achievements, certified courses and marketing of all parties involved. They both are the CV standard. We today evolve their standard in a next step: The continuous, third party certified irrevocable Curriculum Vitae.

A certified curriculum vitae could help unemployment. Personal devices connect to Internet of things devices and data centers and feed continuously an irrevocable an appropriate blockchain. Later on; recruiting agencies use artificial intelligent data science software to find the right job for every worker. Definitely our provided solution is more dangerous that the problem that is supposed to solve but it is an option. With legislative actions and recruiting companies support could solve the contradictory tug-of-war civil rights protection and productivity puzzle.

The primitive workflow of our idea goes like this

- The unemployed gives permission to be recorded for specific skills.

- IoT devices report these skills to a specific BlockChain irrevocably to the eternity.

- Companies, Banks and Public interest agencies report data to the Blockchain in a more concise form.

- Later on; Recruiting agencies use Data Science techniques to find the right person for a specific job.

There are unlimited methodology variations and implementation details for GDPR compliance, actual unemployment, IoT cost and business development requirements. 


\section{Macrothink \\ International Journal of Management Innovation Systems \\ ISSN 1943-1384 \\ 2018, Vol. 3, No. 1}

\section{Curriculum Vitae Data Structure}

Previous generation definition of time series analysis began to be laid in the late nineteenth century and were made possible by regression and correlation coefficient and later (Galton, 1888, 1890) and of Karl Pearson coevolution (Pearson, 1896; Pearson \& Filon, 1898). They are actually primitive math structures with two major proposed alterations-corrections proposals. An inventor from Sofia presented the "realistic time series concept" (Zisopoulos, 2017) where Time-Series gain wide acceptance in Realistic tempo spatial structure. On the other hand, Mathworks developers changed the name of time series "TS" to "Tables series" a very good marketing tool for their MATLAB but also a major progression for a two-dimensional table older than our civilization.

The modified Time-Series is used to store work history and skills, the most important part of the CV. Every moment of our work life is recorded accordingly. A number of moments formulate an incident and a number of incidents constitute a worker's day. However, the actual SQL data structure is not that simple. Variations of the primary concept are:

WHERE; The initial three-dimensional data could be normal three-dimensional data, latitude-longitude-latitude data, inertial calculated coordinates, IP number of generating and receiving device, etc.

WHEN; The second element of temporospatial pattern is more complicated. The basic ISO Date format is assumed with variations for different IoT and operating systems. Somehow, we also need to record duration, sampling accuracy and others similar data.

WHO; There are three types of persons the assignee person, the auditor, and the Subject of the personal data processing. Persons here count also all the Internet of Things devices transmitting to the cloud, they are alive and in the near future they will pay taxes.

WHAT; the answer is almost everything. The concept is "record it now, you could erase it later".

WHY; the data structure to represent the reason of the recording is equally complex like the sad fact that unemployment is increasing every day.

HOW; the methodology is limited only by the creativity of the recruiting agencies.

The most important limitation to our CV data structure is the GDPR legislation. Processing personal data is generally prohibited, except six cases mentioned in the General Data Protection Regulation (GDPR): consent, contract, legal obligations, vital interests of the data subject, public interest and legitimate interest as stated in Article 6(1) GDPR (Zarsky, 2016; Sclater, 2017; Bu-Pasha, 2016).

\section{Semi-Automatic Data Collection}

Every jobless person collects data for his presence in the business area. These data are collected from various IoT sources. The list is unlimited:

- Internet of things 


\section{Macrothink

- Word, Excel computer file headers

- URL fingerprints

- Data Centers \& Banks Big Data

Today recruiting agencies like CEDEFOP (Schmidt, 2004; Mitchell, 2004) depended companies and LinkedIn (Zide, 2014; Gibbs, 2015) use a type of certified external reference to the curriculum vitae. On the other head Udemy courses won the online training competition primarily due to reporting a rather secure prove of training certificate. This Udemy information to the secure LinkedIn site is a perfect example of information collection exploited to curriculum vitae.

\subsection{Sensors, Internet of Things}

Once upon a time there were sensors or PLCs reporting to dedicated computers and Intranets. Today a vast number of similar devices having their own IP reporting direct to the cloud. Connection to these Internet servers is free but this is rapidly changing. They produce enormous amount of structured data and the individual worker could assign to a selected subset of them to represent his labor life.

Three IoT management-operating systems are available today:

- Microsoft; Windows 10 IoT operating system for devices under the Azure IoT Suite.

- Google Android things; Cloud IoT is a fully managed service that allows you to easily and securely connect, manage, and feed data from millions of globally dispersed devices.

- Team view; The dominated remote-control company offers a more rigid IoT management system capable to handle Curriculum Vitae operations outside the dominated the world companies.

\subsection{Computer File}

Every worker in almost all jobs uses computer software every day. The simplest program is Microsoft Word. There are programs in GitHub and a specific application in the first Blockchain magazine (Muehlemann, 2017) that read a Word file without reading it. The program could read only a specific information from a Word file like "total editing time".

The procedure is straightforward:

- The user writes or edits a Word file and saves it to the local disk or up to the Internet cloud.

- Once per day voluntarily permits a Github certified crawler to read certain part of the file.

- The program reports the info to the Curriculum Vitae Blockchain irrevocably but certainly with access limitations. 


\subsection{URL Fingerprint}

A whole generation of new browsers has the main unique feature that they preserve the personal data of the user. TOR, Brave and EPIC browsers claim total failure of any tracing attempt. This ability is GDPR compatible but in our case, we want to prove our work. We propose a new URL-fingerprint browser that will do the exact opposite. The Blockchain curriculum provider releases this FINGERPRINT browser. In order to conclude an assigned task, the user visits various sites and applications and all the activity is recorded and reported accordingly.

Of course, the user will try to cheat. He could use another browser for weather info, chat talking, Facebook and other similar annoying time-consuming programs. Such a usage delays the task to be accomplished and degrades all job statistics. Later on, statistics could prove that this specific worker is slow generally or only for specific URL classes. He is not eligible for this job; his URL stats do comply with job description statistics.

\subsection{Commercial Bank Feed}

The absolute from of proof is money (Money talks, Show me the money Berger, 2012; Myers, 2012). In a number of countries in order to prove your working experience a money payment is required. Commercial Banks, Data Centers and other similar structures have unlimited personal data. Most of these data could eventually concern the working expertise of a person. Actually, Data Science (Liao, 2012; Brodei, 2012; Chen, 2012) artificial intelligence methodologies could process these data efficiently. Initial raw data examples that a worker could permit to feed the Blockchain are:

- A parking ticket, a café receipt and a train ticket near the workplace area gives exact temprospatiale data.

- A Visa payment for a specific book or magazine, a scientific conference payment or a Udemy payment is a secure qualification information valuable to your future work.

- A google advertisement payment is a secure prove for a semiprofessional activity.

\section{Blockchain Layout}

The BlockChain etymology is not right for linguistics and etymology reasons. We find more appropriate a "Distributed Ledger Hashed Blocks" without chains. The chain shapely and historically reminds for convicted prisoners and slaves. There are historical examples in Bible and East Catholic church where confessors sold themselves as slaves to achieve higher hierarchy confession level. Various researchers face the new technology in all aspects of life. Al-Saqaf (2017) tried to contribute to that body of scholarship by exploring blockchain technology's potential applications, and their limits, in areas that intersect with social impact, including human rights. Scott (2017) declared cryptocurrencies and blockchain technology may help develop organizations that seek to build social and solidarity - based finance. White (2017) recently stated that business managers need to understand the potential impact and threat of blockchain applications in order to gain and maintain competitive advantage. Blockchain applications appear to offer considerable performance improvement and 


\section{Al Macrothink}

International Journal of Management Innovation Systems

ISSN 1943-1384 2018, Vol. 3, No. 1

commercialization opportunities.

In our time a self-slavery could be inevitable for the well-educated workers in order to find the appropriate job. Initially a freely given, specific, informed and unambiguous consent must be given for all their professional data to be recorded. So far so good but there is a new unreversed step. They also permitted the quasi-registration in an irrevocable chain of all relevant information.

This is an unacceptable situation for reasons like:

- Christian; Forgiveness is reduced dramatically.

- It concerns a new slavery situation.

- It could evolve in a "Big brother" situation.

We do not afraid this non-Christian, Big-Brother new slavery situation. We rely on Bible again in

Table 1. Matthew 12:36

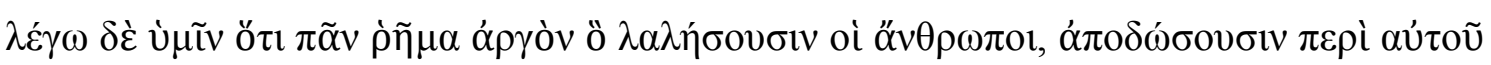

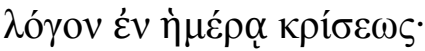

36But I tell you that everyone will have to give account on the day of judgment for every empty word they have spoken

Staying in Bible the most famous and important chain of the world are in Basilica di San Pietro in Vincoli (Saint Peter in Chains) of Saint Peter's chains when he was imprisoned in Jerusalem (Sidon). In the image below times the chain of blocks for prisoners has evolved in the BlockChain in exact the same way.

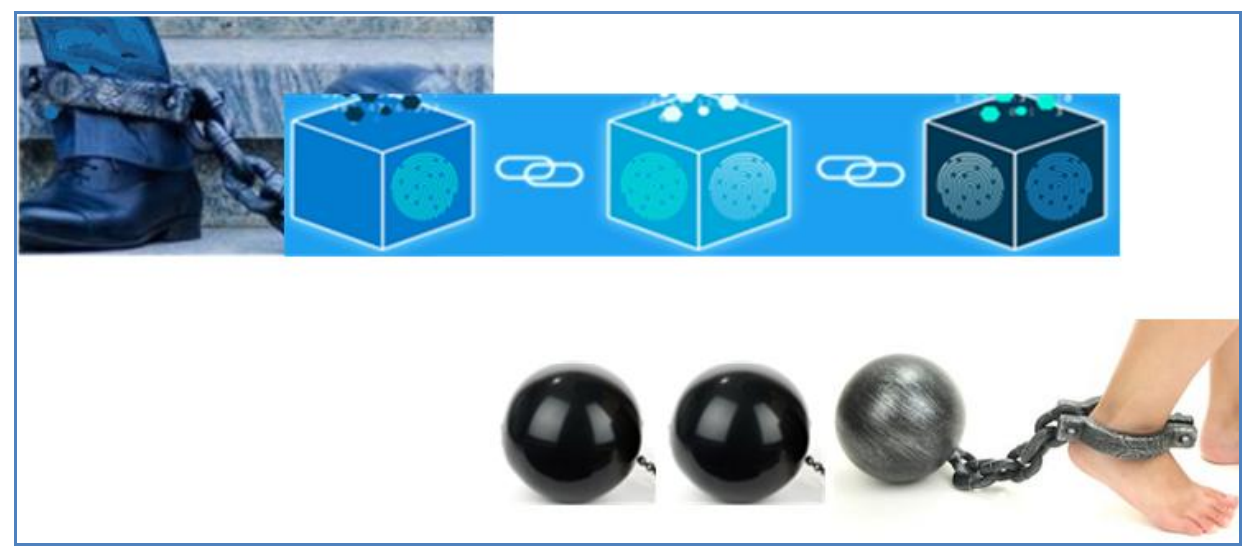

Figure 1. Times are passing, things remain unchained: Tradional and modern Blockchains 


\section{$\triangle$ Macrothink}

International Journal of Management Innovation Systems

ISSN 1943-1384

Blockchain is block of interconnected hashes. Major BlockChain feature is the collapse of the whole block ecosystem if a single block is altered. This reminds us the DNA structure. When nodes start changing no next generation is possible and death is very close. DNA structure is better than BlockChain because no instant failure occurs when chain is broken.

\section{BIGDATA Processing, Life under Chains and Blocks}

Various researchers gave descriptive names for Big data.

Big Data is described by IBM in terms of four dimensions: volume, variety, velocity, and veracity (Herchel, 2017). Over the recent years, the volume of worldwide data has exploded from various digital devices that continuously generate massive amounts of heterogeneous, structured or unstructured data, resulting in what is now called "big data" (Kambatla, 2014). Big data refers to rapidly growing amounts of data for which traditional database mechanisms have become inefficient in terms of storage, processing and analysis (Manyika, 2011; Nesbit 2018; Yaqoob, 2016).

A single person detailed professional achievements generate a typical BIGDATA huge database. To process this database, we used $\mathrm{R}$ language a programming language so that you create our objects, functions, and packages.

\section{Discussion}

There are severe problems to solve and additional systems to be prepared in order to present to the science and society a viable alternative

The main issue is the irreversible order of the data feed from the Blockchain to the reading agent. We need a balance between two contradictory issues:

- The BlockChain stores all data forever unconditionally and this is the cornerstone of the methodology.

- The person as a subject of data retrieval and processing occasionally does not wat to grant access to the recruiting agency.

A number of solutions are proposed for this inconsistent:

- Variable access consent to data reading authorities.

- R language statistical preprocessing to eliminate non-ethic data on the BlockChain.

- Similar programming to smooth extreme life incidents.

- A type of reward or payment (to whom?) to eliminate misleading data.

\section{Conclusion}

According to GDPR the necessary consent must be freely given, specific, informed and unambiguous. In order to obtain freely given consent, it must be given on a voluntary basis. The element "free" implies a real choice by the data subject. Any element of inappropriate pressure or influence which could affect the outcome of that choice renders the consent 


\section{MInstitute Macrothink $_{\text {Int }}$}

International Journal of Management Innovation Systems

ISSN 1943-1384

invalid. In the real world there is strong blackmail with obvious answer for the two worlds around the unemployment line.

There are two options for Recording and Hiring in a job:

- No BlockChain, No Job

- Yes, to Blockchain, Yes to a new Job

We attempted a primitive social research. In our University young people, they prefer to follow the blockchain recruiting route at a rate of $96 \%$. In a prefecture only $1 \%$ endorses the technology for unemployment. This was expected. For the people unemployment in Greece is $20 \%$ but this denotes 1 million persons $100 \%$ without work, a basic constitutional privilege.

\section{Acknowledgements}

Initially I, Athanasios Zisopoulos, thank the only person in the world that supported my initial effort: Dikaios Tserkezos from University of Crete.

We thank our professors from Aristoteles University of Thessaloniki under Saint Dimitrios blessing and Sofia University under Saint Clementios Ochridksi blessing.

\section{References}

Al-Saqaf, W., \& Seidler, N. (2017). Blockchain technology for social impact: opportunities and challenges ahead. Journal of Cyber Policy, 2(3), 338-354. https://doi.org/10.1080/23738871.2017.1400084

Berger, B., \& Newman, S. (Eds.). (2012). Money talks: In therapy, society, and life (Vol. 13). Routledge.

Beutter Manus, S. J. (2009). Librarian in the Classroom: An Embedded Approach to Music Information Literacy for First-Year Undergraduates. Notes, 66(2), 249-261. Music Library Association. https://doi.org/10.1353/not.0.0259

Brodie, M. L., Mylopoulos, J., \& Schmidt, J. W. (Eds.). (2012). On conceptual modelling: Perspectives from artificial intelligence, databases, and programming languages. Springer Science \& Business Media.

Bu-Pasha, S., Alen-Savikko, A., Makinen, J., Guinness, R., \& Korpisaari, P. (2016). EU Law perspectives on location data privacy in smartphones and informed consent for transparency. Eur. Data Prot. L. Rev., 2, 312. https://doi.org/10.21552/EDPL/2016/3/7

Chen, H., Chiang, R., \& Storey, V. (2012). Business Intelligence and Analytics: From Big Data to Big Impact. MIS Quarterly, 36(4), 1165-1188. https://doi.org/10.2307/41703503

Dellavalle, R. P., Hester, E. J., Heilig, L. F., Drake, A. L., Kuntzman, J. W., Graber, M., \& Schilling, L. M. (2003). Going, going, gone: Lost Internet references.

Feiler, L. et al. (2018). The EU General Data Protection Regulation (GDPR): A Commentary. Globe Law and Business. 


\section{$\triangle$ Macrothink}

International Journal of Management Innovation Systems ISSN 1943-1384

Galton, F. (1888). Correlation and their measurement of child head from antopometric data. Proc. Roy. Sco, 45, 35-44.

Galton, F. (1890). Kinship and correlation. The North American Review, 150(401), 419-431. Pearson, K. (1896). Mathematical contributions to the theory of evolution. III. Regression, heredity, and panmixia. Philosophical Transactions of the Royal Society of London. Series A, containing papers of a mathematical or physical character, 187, 253-318.

Gibbs, C., MacDonald, F., \& MacKay, K. (2015). Social media usage in hotel human resources: Recruitment, hiring and communication. International Journal of Contemporary Hospitality Management, 27(2), 170-184. https://doi.org/10.1108/IJCHM-05-2013-0194

Herschel, R., \& Miori, V. M. (2017). Ethics \& Big Data. Technology in Society, 49, 31-36. https://doi.org/10.1016/j.techsoc.2017.03.003

Kambatla, K., Kollias, G., Kumar, V., \& Grama, A. (2014). Trends in big data analytics. Journal of Parallel and Distributed Computing, 74(7), 2561-2573. https://doi.org/10.1016/j.jpdc.2014.01.003

Liao, S. H., Chu, P. H., \& Hsiao, P. Y. (2012). Data mining techniques and applications-A decade review from 2000 to 2011. Expert Systems with Applications, 39(12), 11303-11311. https://doi.org/10.1016/j.eswa.2012.02.063

Manyika, J., Chui, M., Brown, B., Bughin, J., Dobbs, R., Roxburgh, C., \& Byers, A. H. (2011). Big data: The next frontier for innovation, competition, and productivity.

Miles, I. (2011). From knowledge-intensive services to knowledge-intensive service systems. International Journal of Services Technology and Management, 16(2), 141-159. https://doi.org/10.1504/IJSTM.2011.042593

Mitchell, A., \& Savill-Smith, C. (2004). The use of computer and video games for learning: A review of the literature.

Muehlemann, A. (2017). Sentiment protocol: A decentralized protocol leveraging crowd sourced wisdom.

Myers, K. (2012). Show me the money. Money Talks: In Therapy, Society, and Life, 13, 143.

Nesbitt, C., \& McCaslin, J. (2018). Building the best portfolio for career progression. Surgery (Oxford), 36(9), 478-482. https://doi.org/10.1016/j.mpsur.2018.07.007

Pearson, K., \& Filon, L. N. G. (1898). Mathematical contributions to the theory of evolution. IV. On the probable errors of frequency constants and on the influence of random selection on variation and correlation. Proceedings of the Royal Society of London, 62(379-387), 173-176. https://doi.org/10.1098/rsta.1898.0007

Schmidt, S. L., Schomann, K., \& Tessaring, M. (2003). Early Identification of Skill Needs in Europe. CEDEFOP Reference Series. Bernan Associates, 4611-F Assembly Drive, Lanham, MD 20706-4391. 


\section{Macrothink}

International Journal of Management Innovation Systems

ISSN 1943-1384

Sclater, N. (2017). Consent and the GDPR: what approaches are universities taking. Effective Learning Analytics. https://doi.org/10.4324/9781315679563

Scott, B., Loonam, J., \& Kumar, V. (2017). Exploring the rise of blockchain technology: Towards distributed collaborative organizations. Strategic Change, 26(5), 423-428. https://doi.org/10.1002/jsc.2142

Siddiqa, A., Hashem, I. A. T., Yaqoob, I., Marjani, M., Shamshirband, S., Gani, A., \& Nasaruddin, F. (2016). A survey of big data management: Taxonomy and state-of-the-art. Journal of Network and Computer Applications, 71, 151-166. https://doi.org/10.1016/j.jnca.2016.04.008

Skule, S. (2004). Learning conditions at work: A framework to understand and assess informal learning in the workplace. International Journal of Training and Development, 8(1), 8-20. https://doi.org/10.1111/j.1360-3736.2004.00192.x

White, G. R. (2017). Future applications of blockchain in business and management: A Delphi study. Strategic Change, 26(5), 439-451. https://doi.org/10.1002/jsc.2144

Yaqoob, I., et al. (2016). "Big data: From beginning to future. International Journal of $\begin{array}{lllll}\text { Information } \quad \text { Management } & \text { 36(6, } & \text { Part } & \text { B), } & \text { 1231-1247. }\end{array}$ https://doi.org/10.1016/j.ijinfomgt.2016.07.009

Zarsky, T. Z. (2016). Incompatible: The GDPR in the Age of Big Data. Seton Hall L. Rev., 47, 995.

Zide, J., Elman, B., \& Shahani-Denning, C. (2014). LinkedIn and recruitment: How profiles differ across occupations. Employee Relations, 36(5), 583-604. https://doi.org/10.1108/ER-07-2013-0086

\section{Copyright Disclaimer}

Copyright for this article is retained by the author(s), with first publication rights granted to the journal.

This is an open-access article distributed under the terms and conditions of the Creative Commons Attribution license (http://creativecommons.org/licenses/by/3.0/). 